\title{
Gastroenteropancreatic neuroendocrine tumor of the accessory papilla of the duodenum: a case report
}

\author{
Kosei Takagi* (D, Yuzo Umeda, Ryuichi Yoshida, Kazuhiro Yoshida, Kazuya Yasui, Hiroki Sato, Takahito Yagi and
}

Toshiyoshi Fujiwara

\begin{abstract}
Background: Contrary to the increasing incidence of gastroenteropancreatic neuroendocrine tumors (GEP-NETs), GEP-NETs of the accessory papilla of the duodenum are extremely rare. Furthermore, there have been no recommendations regarding the treatment strategy for GEP-NETs of the accessory papilla of the duodenum. We present a case of GEP-NET of the accessory papilla of the duodenum successfully treated with robotic pancreatoduodenectomy.

Case presentation: A case of a 70-year-old complaining of no symptoms was diagnosed with GEP-NET of the accessory papilla of the duodenum. A 8-mm tumor was located at the submucosal layer with a biopsy demonstrating a neuroendocrine tumor grade 1. The patient underwent robotic pancreatoduodenectomy as curative resection for the tumor. The total operative time was $406 \mathrm{~min}$ with an estimated blood loss of $150 \mathrm{~mL}$. The histological examination revealed a well-differentiated neuroendocrine tumor with low Ki-67 index $(<1 \%)$. In the posterior areas of the pancreas, the lymph node metastases were detected. The patient was followed up for 6 months with no recurrence postoperatively.
\end{abstract}

Conclusions: Considering the potential risks of the lymph node metastases, the standard treatment strategy for GEPNETs of the accessory papilla of the duodenum should be radical resection with pancreatoduodenectomy. Minimally invasive approach can be the alternative to the conventional open surgery.

Keywords: Accessory papilla of the duodenum, Neuroendocrine tumor, Carcinoid tumor

\section{Background}

Although the incidence of gastroenteropancreatic neuroendocrine tumors (GEP-NETs) has increased, GEPNETs of the duodenum are rare [1,2]. Furthermore, GEP-NETs of the accessory papilla of the duodenum are extremely rare. To date, there have been only nine cases of GEP-NETs of the accessory papilla of the duodenum reported in the English literature [3-11]. We hereby present a case of GEP-NET of the accessory

\footnotetext{
*Correspondence: kotakagi15@gmail.com

Department of Gastroenterological Surgery, Okayama University

Graduate School of Medicine, Dentistry, and Pharmaceutical Sciences,

2-5-1 Shikata-cho, Kita-ku, Okayama 700-8558, Japan
}

papilla of the duodenum successfully treated with robotic pancreatoduodenectomy.

\section{Case presentation}

A 70-year-old man was referred to our hospital for further examination of a tumor at the duodenum. Esophagogastroduodenoscopy identified a submucosal tumor at the accessory papilla in the second part of the duodenum (Fig. 1a, b). Endoscopic ultrasonography showed a 8-mm hypoechoic mass in the submucosal layer (Fig. 1c), and endoscopic biopsy demonstrated a well-differentiated neuroendocrine tumor with a low Ki-67 index suggesting grade 1 (G1). Computed tomography (CT) revealed a highly enhanced tumor in the early phase, showing 


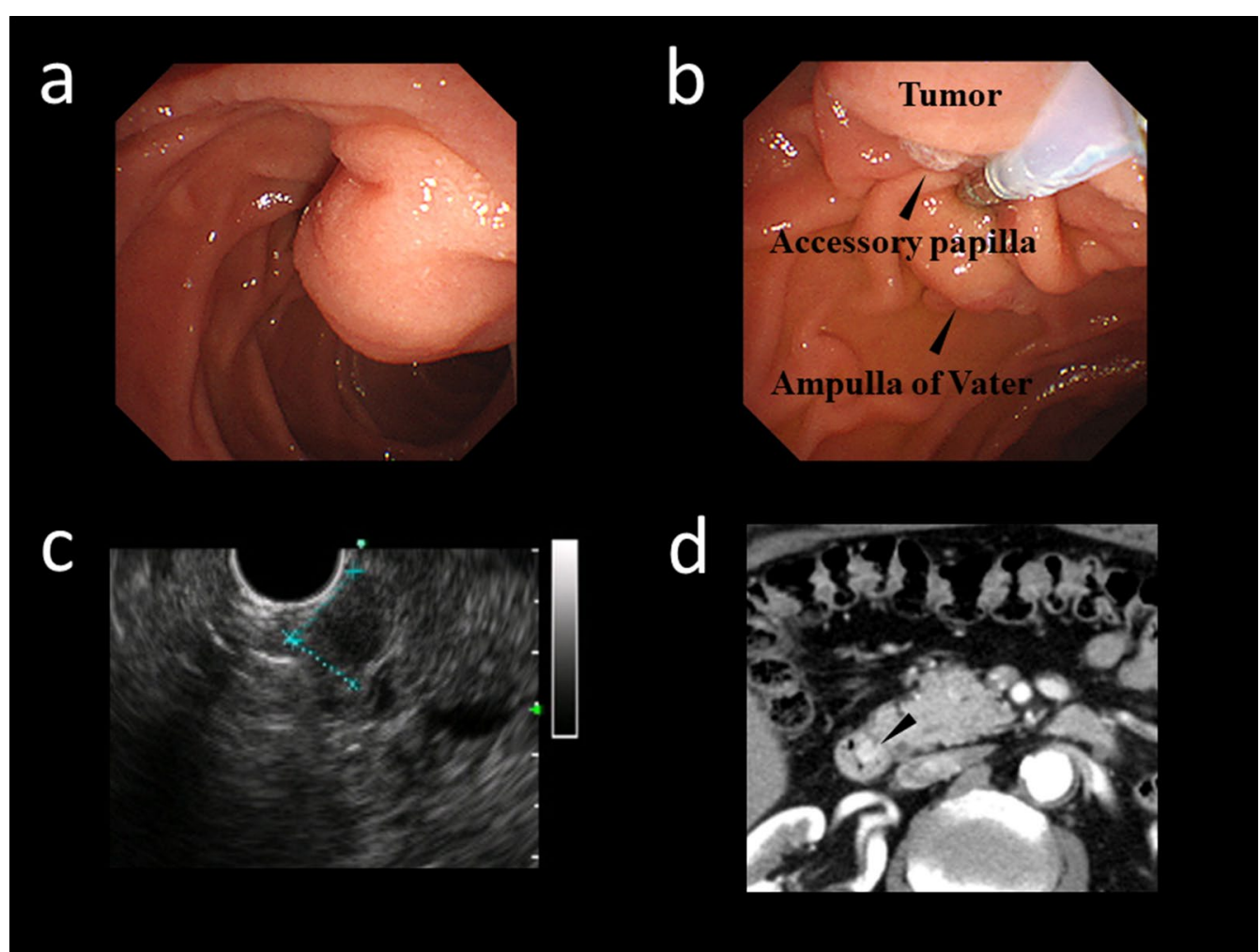

Fig. 1 Endoscopic examination showed a 8-mm submucosal tumor at the accessory papilla in the second part of the duodenum (a). The relationship between the tumor, the accessory papilla and the ampulla of Vater is demonstrated (b). Endoscopic ultrasonography demonstrated hypoechoic mass in the submucosal layer (c). Computed tomography (CT) revealed the highly enhanced tumor in the early phase with no metastatic lesion including the lymph node and the liver (d)

neither apparent lymph node metastases nor distant metastases (Fig. 1d). Magnetic resonance imaging (MRI) also detected no lymph node and liver metastases.

Although there have been no recommendations regarding the treatment strategy for GEP-NETs of the accessory papilla of the duodenum, radical resection with pancreatoduodenectomy has been recommended as the first-line treatment for GEP-NETs of the ampulla of Vater due to relatively poor prognosis [12]. Furthermore, endoscopic intervention was considered to be difficult due to the potential risk of the proper muscular layer damage of the duodenum as well as location at the accessory papilla. Therefore robotic pancreatoduodenectomy with lymph node dissection was performed.

Our standardized protocol for robotic pancreatoduodenectomy was previously reported [13]. Following the kocherization of the duodenum, the jejunum and the stomach are divided. The hepatoduodenal ligament was dissected to perform hilar lymphadenectomy. After the transection of the pancreas on the superior mesenteric vein, the uncinate dissection was performed along the superior mesenteric artery. Thereafter the specimen was removed through the Pfannenstiel incision. The reconstruction included the pancreaticojejunostomy with interrupted two-layer modified Blumgart method, the hepaticojejunostomy with interrupted sutures, and the gastrojejunostomy with the robotic-sewn anastomosis.

The total operative time was $406 \mathrm{~min}$, and the estimated blood loss was $150 \mathrm{~mL}$. Uneventful postoperative course including no complications was observed with the patient being discharged on postoperative day 8. The final histological diagnosis was neuroendocrine tumor G1 based on the findings of synaptophysin positive, chromogranin A positive, and Ki-67 index $(<1 \%)$ (Fig. 2). The presence of lymphovascular invasion was not found in the D2-40 immunostaining. Surprisingly, the lymph node metastases were confirmed at posterior areas of the pancreas (station 13). Regarding immunohistochemical staining of endocrine cells, the insulin-, gastrin- and somatostatin-immunoreactive endocrine cells were not detected.

The patient was followed up for 6 months without recurrence postoperatively. 


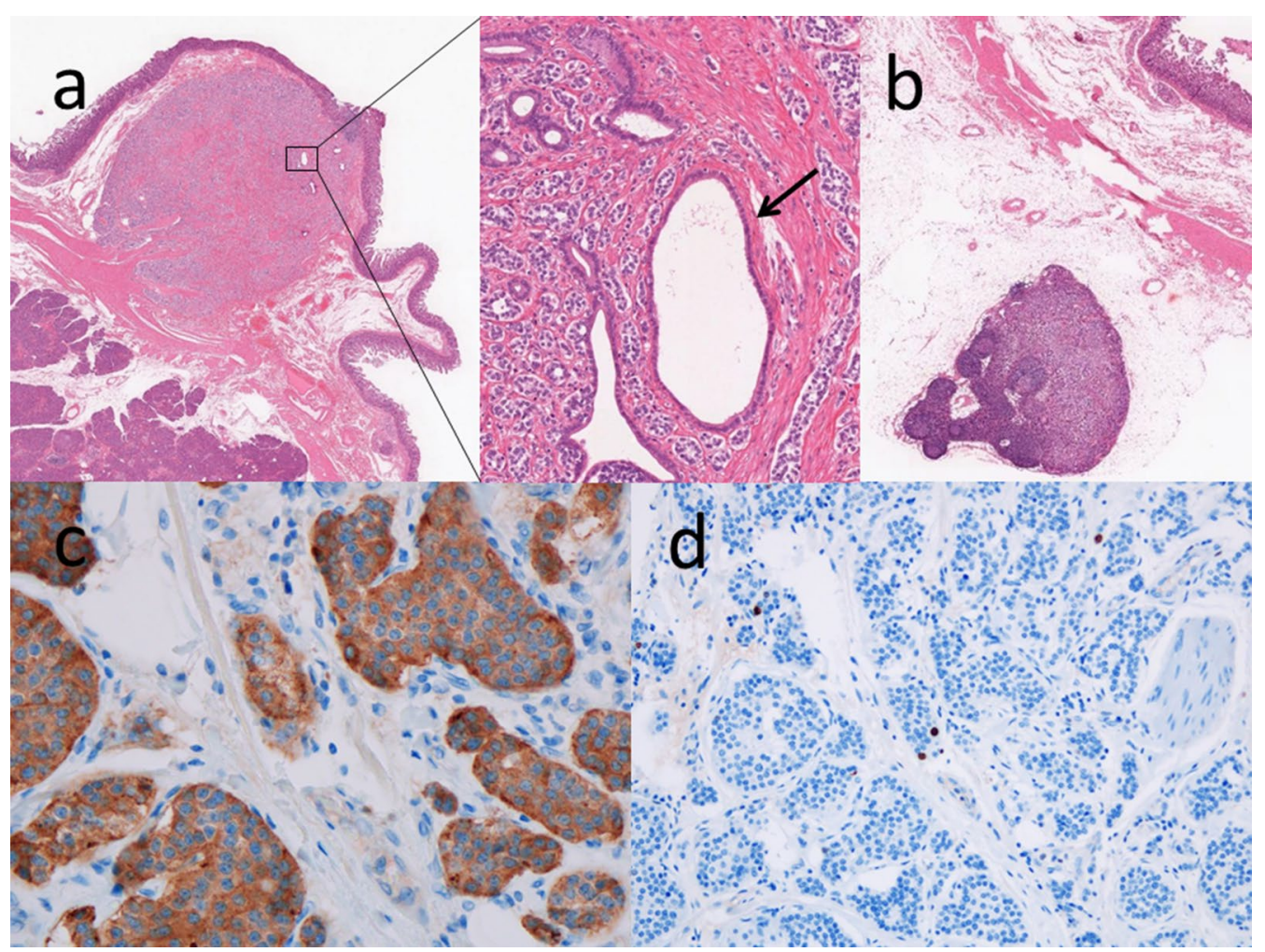

Fig. 2 The tumor at the accessory papilla as the accessory pancreatic duct (arrow) is shown. Hematoxylin and eosin stain demonstrating nesting pattern of mostly uniform cells with central ovoid nucleus (a). The lymph node metastasis (b). Synaptophysin showing positive (c). Ki-67 index stain showing $<1 \%$ proliferation $(\mathbf{d})$

\section{Discussion}

To our knowledge, this is the first description on GEPNETs of the accessory papilla of the duodenum with lymph node metastases successfully treated with robotic pancreatoduodenectomy. The present case indicates that a well-differentiated neuroendocrine tumor G1 with less than $1 \mathrm{~cm}$ at the accessory papilla of the duodenum could have the potential risks of the lymph node metastases. Therefore we suggest that radical surgical resection with pancreatoduodenectomy instead of local excision should be the first-line treatment option for GEP-NETs of the accessory papilla of the duodenum.

Contrary to the increasing number of GEP-NETs, GEPNETs of the accessory papilla of the duodenum are very rare. The characteristics in reported cases of GEP-NETs of the accessory papilla of the duodenum are demonstrated in Table 1 [3-11]. The average tumor size was approximately $11 \mathrm{~mm}$. Most of cases developed symptoms including pain, diarrhea, and weight loss. Regarding the type of intervention, five cases out of ten received local excision with surgically $(n=4)$ or endoscopically $(n=1)$. Although the margin of resected tumor was confirmed to be positive in a case with endoscopic intervention, no recurrences during the follow-up were observed in five cases undergoing local excision. In contrast, five cases underwent radical resection with pancreatoduodenectomy. The results of case series suggested the efficacy of radical resection for the tumors. Surprisingly, lymph node metastases at the resected regional areas were identified in four cases out of five. Therefore, it should be recognized that GEP-NETs of the accessory papilla of the duodenum could metastasize to the lymph nodes regardless of size of the tumor.

With respect to treatment strategy, it suggests that pancreatoduodenectomy should be the first-line treatment for GEP-NETs of the accessory papilla of the duodenum. In the light of malignant potential, radical resection should be considered even for small primary tumors. Minimally invasive pancreatoduodenectomy can be optional given the safety and oncologic efficacy of minimally invasive surgery [14]. In contrast, surgical or endoscopic local excision should not be recommended as curative treatment, but can be an alternative. In addition, local excision with regional lymph node dissection or sentinel node dissection could be an option as less invasive surgical intervention. Prior to performing local excision, accurate radiographic evaluations are important for localizing tumors. CT and MRI are the most common 
Table 1 Characteristics in reported cases of gastroenteropancreatic neuroendocrine tumors of the accessory papilla of the duodenum

\begin{tabular}{|c|c|c|c|c|c|c|}
\hline Reports (year) & Age/sex & Symptom & Size $(\mathrm{mm})$ & Treatment & Pathology & Outcome \\
\hline Malone et al. (1985) [3] & $46 / \mathrm{M}$ & $\begin{array}{l}\text { Abdominal pain } \\
\text { Anorexia } \\
\text { Steatorrhea } \\
\text { Wight loss }\end{array}$ & $5-7.5$ & Local excision (Surgically) & Somatostatinoma & No recurrence, 16 months \\
\hline Borobia et al. (2001) [4] & $46 / F$ & $\begin{array}{l}\text { Diarrhea } \\
\text { Steatorrhea }\end{array}$ & NA & Local excision (Surgically) & Neuroendocrine tumor & No recurrence, 3 years \\
\hline Singh et al. (2003) [5] & $35 / F$ & Pancreatitis & 10 & $\begin{array}{l}\text { Local excision } \\
\text { Sphincteroplasty (surgi- } \\
\text { cally) }\end{array}$ & $\begin{array}{l}\text { Carcinoid } \\
\text { Negative margin }\end{array}$ & No recurrence, 6 months \\
\hline Wang et al. (2005) [6] & $50 / \mathrm{M}$ & $\begin{array}{l}\text { Multiple melenas } \\
\text { Polycythemia vera }\end{array}$ & 9 & Local excision (surgically) & Carcinoid & No recurrence, 3 years \\
\hline Itoi et al. (2007) [7] & $65 / M$ & No & 12 & $\begin{array}{l}\text { Local excision (endo- } \\
\text { scopically) }\end{array}$ & $\begin{array}{l}\text { Invasive carcinoid tumor } \\
\text { Positive margin }\end{array}$ & No recurrence, 4 years \\
\hline Stömmer et al. (1987) [8] & $56 / F$ & $\begin{array}{l}\text { Jaundice } \\
\text { Wight loss }\end{array}$ & 3 & $\mathrm{PD}$ & $\begin{array}{l}\text { Somatostatinoma } \\
\text { No LNM }\end{array}$ & NA \\
\hline Lowes et al. (1988) [9] & $50 / F$ & $\begin{array}{l}\text { Abdominal pain } \\
\text { Diarrhea } \\
\text { Wight loss }\end{array}$ & 12 & PD & $\begin{array}{l}\text { Somatostatinoma } \\
\text { LNM (regional areas) }\end{array}$ & NA \\
\hline $\begin{array}{l}\text { Waisberg et al. (2006) } \\
\text { [10] }\end{array}$ & $57 / F$ & $\begin{array}{l}\text { Abdominal pain } \\
\text { Diarrhea } \\
\text { Weight loss }\end{array}$ & 27 & PD & $\begin{array}{l}\text { Carcinoid (somatostati- } \\
\text { noma) } \\
\text { LNM (regional areas) }\end{array}$ & Death, POD 21 \\
\hline Kim et al. (2010) [11] & $56 / F$ & Abdominal pain & 12 & PD & $\begin{array}{l}\text { Carcinoid } \\
\text { Vascular invasion } \\
\text { No perineural invasion } \\
\text { LNM (regional areas) }\end{array}$ & NA \\
\hline Our case & $70 / \mathrm{M}$ & No & 8 & Robotic PD & $\begin{array}{l}\text { Neuroendocrine tumor } \\
\text { Well-differentiated (G1) } \\
\text { No lymphovascular } \\
\text { invasion } \\
\text { LNM (regional areas) }\end{array}$ & No recurrence, 6 months \\
\hline
\end{tabular}

$M$ male, $F$ female, $P D$ pancreatoduodenectomy, LNM lymph node metastasis, $N A$ not available

modalities used for evaluation of the primary tumor and metastasis [15]. Moreover, somatostatin receptor scintigraphy has improved accuracy to detect smaller GEP-NETs [15]. Accordingly, local excision should be performed only in limited cases such as high-risk patients for surgery or patients with no lymph node metastases. However, further clinicopathological evidence including short-term and long-term outcomes on GEP-NETs of the accessory papilla of the duodenum is needed.

In conclusion, we present an extremely rare case of GEP-NET of the accessory papilla of the duodenum accompanied by lymph node metastases. Although carcinogenic mechanism of this tumor remains uncertain because of the limited reports, radical resection with pancreatoduodenectomy should be performed due to the potential risks of the lymph node metastases. Minimally invasive approach should be considered as the alternative to the conventional open surgery.

\begin{abstract}
Authors' contributions
All authors contributed to this work, and approved the final manuscript.

\section{Funding}

Financial support was received from Japan Society for the Promotion of Science (JSPS KAKENHI Grant Number JP 21K16447).
\end{abstract}

\section{Availability of data and materials}

Data supporting the conclusions are included in the article.

\section{Declarations}

Ethics approval and consent to participate Not applicable.

\section{Consent for publication}

Written informed consent was obtained from the patient for publication of this case report and any accompanying images.

\section{Competing interests}

The authors have no conflicts of interest to declare.

Received: 22 May 2021 Accepted: 22 June 2021

Published online: 30 June 2021

\section{Abbreviations}

GEP-NET: Gastroenteropancreatic neuroendocrine tumor; CT: Computed tomography; MRI: Magnetic resonance imaging. 


\section{References}

1. Pavel M, Öberg K, Falconi M, et al. Gastroenteropancreatic neuroendocrine neoplasms: ESMO Clinical Practice Guidelines for diagnosis, treatment and follow-up. Ann Oncol. 2020;31:844-60.

2. Dasari A, Shen C, Halperin D, et al. Trends in the incidence, prevalence, and survival outcomes in patients with neuroendocrine tumors in the United States. JAMA Oncol. 2017:3:1335-42.

3. Malone MJ, Silverman ML, Braasch JW, et al. Early somatostatinoma of the papilla of the duct of Santorini. Arch Surg. 1985:120:1381-3.

4. Borobia FG, Fabregat J, Jorba R, et al. Exocrine pancreatic insufficiency caused by a somatostatinoma of the minor and major duodenal papilla in a patient with neurofibromatosis. Eur J Surg. 2001;167:154-6.

5. Singh W, Bhutani MS, Draganov P. Carcinoid of the minor papilla in incomplete pancreas divisum presenting as acute relapsing pancreatitis. Pancreas. 2003;27:96-7.

6. Wang HY, Chen MJ, Yang TL, et al. Carcinoid tumor of the duodenum and accessory papilla associated with polycythemia vera. World J Gastroenterol. 2005:11:3794-6.

7. Itoi T, Sofuni A, Itokawa F, et al. Endoscopic resection of carcinoid of the minor duodenal papilla. World J Gastroenterol. 2007;13:3763-4

8. Stömmer PE, Stolte M, Seifert E. Somatostatinoma of Vater's papilla and of the minor papilla. Cancer. 1987;60:232-5.

9. Lowes JR, Rode J, Lees WR, et al. Obstructive pancreatitis: unusual causes of chronic pancreatitis. Br J Surg. 1988;75:1129-33.
10. Waisberg J, de Matos LL, Waisberg DR, et al. Carcinoid of the minor duodenal papilla associated with pancreas divisum: Case report and review of the literature. Clinics (Sao Paulo). 2006:61:365-8.

11. Kim YG, Kim TN, Kim KO. Carcinoid tumor of the minor papilla in complete pancreas divisum presenting as recurrent abdominal pain. BMC Gastroenterol. 2010;10:17

12. Hwang $S$, Lee $S G$, Lee $Y$ J, et al. Radical surgical resection for carcinoid tumors of the ampulla. J Gastrointest Surg. 2008;12:713-7.

13. Takagi $K$, Umeda $Y$, Yoshida $R$, et al. Surgical training model and safe implementation of robotic pancreatoduodenectomy in Japan: a technical note. World J Surg Oncol. 2021;19:55.

14. Hwang HK, Song KB, Park M, et al. Minimally invasive versus open pancreatectomy for right-sided and left-sided G1/G2 nonfunctioning pancreatic neuroendocrine tumors: a multicenter matched analysis with an inverse probability of treatment-weighting method. Ann Surg Oncol. 2021. https://doi.org/10.1245/s10434-021-10092-0.

15. Yazdanpanah O, Surapaneni S, Shanah L, et al. Diagnosis and management of gastrointestinal neuroendocrine tumors: a comprehensive literature review. Cureus. 2021;13:e14006.

\section{Publisher's Note}

Springer Nature remains neutral with regard to jurisdictional claims in published maps and institutional affiliations.

\section{Submit your manuscript to a SpringerOpen ${ }^{\circ}$ journal and benefit from:}

- Convenient online submission

- Rigorous peer review

- Open access: articles freely available online

- High visibility within the field

- Retaining the copyright to your article

Submit your next manuscript at $\boldsymbol{\nabla}$ springeropen.com 